\title{
O CÂNONE NA HISTÓRIA DA LITERATURA BRASILEIRA
}

\author{
João Alexandre Barbosa
}

RESUMO: This essay, whose title is a metaphor for what is imaginary in the question of canons, is about brazilian literary canon such it was built by succesive literary histories since the romantic movement. Also as sugested by its title, the main assertion is that each reader has his own canon but anyway imposed by readings experiences. Without defending any specific canon, the essay open the possibility of thinking in the canons formation in accordance with several ways of institutional teachings of literature including and foremost the different histories of literature.

PALAVRAS-CHAVE: literatura, crítica, história, cânone, formação, história, educação, leitura.

Se, no caso das literaturas européias e norte-americana a fixação de cânones literários resultou do aparecimento de grandes ensaios de interpretação da herança cultural do Ocidente, quase sempre movidos por um forte apelo classicizante, dando como resultado uma rígida hierarquização de gêneros, raças e modelos culturais, que somente será abalada pelos movimentos multiculturais de anos recentes, no caso brasileiro a formação do cânone literário seguiu, de bem perto, o próprio desenvolvimento de nossas relações de dependência e de autonomia com vistas às fontes metropolitanas.

Para tanto, contribuiram, sobretudo, os esforços no sentido de estabelecer um corpus de autores e obras identificados como brasileiros e diferenciados das origens européias, em que se destacavam, como não podia deixar de ser, as portuguesas.

Neste sentido, sobreleva o discurso histórico-literário, desde as suas mais incipientes manifestações românticas, passando pela extraordinária sistematização de Sílvio Romero, em fins do século XIX, até às reformulações modernas e contemporâneas.

Foi precisamente um dos autores de importante reformulação contemporâ-

João Alexandre Barbosa é professor de Teoria Literária e Literatura Comparada da USP. 
nea do discurso histórico-literário, Antonio Candido, que, num dos últimos capítulos de sua Formação da Literatura Brasileira, intitulado "Formação do cânone literário", sintetizou, de modo exemplar, a questão tal como foi enfrentada pelos românticos brasileiros.

"A sua longa e constante aspiração - diz ele - foi, com efeito, elaborar uma história literária que exprimisse a imagem da inteligência nacional na seqüência do tempo, -projeto quase coletivo que apenas Ślvio Romero pôde realizar satisfatoriamente, mas para o qual trabalharam gerações de críticos, eruditos e professores, reunindo textos, editando obras, pesquisando biografias, num esforço de meio século que tornou possível a sua História da literatura brasileira, no decênio de 80.

"Visto de hoje, esse esforço semi-secular aparece coerente na sucessão das etapas. Primeiro, o panorama geral, o 'bosquejo', para traçar rapidamente o passado literário; ao lado dele, a antologia dos poucos textos disponíveis, o 'florilégio', ou 'parnaso'. Em seguida, a concentração em cada autor, antes referido rapidamente no panorama: são as biografias literárias, reunidas em 'galerias', em 'pantheons'; ao lado disso, um incremento de interesse pelos textos, que se desejam mais completos; são as edições, reedições, acompanhadas geralmente de notas explicativas e informação biográfica. Depois, a tentativa de elaborar a história, o livro documentário, construído sobre os elementos citados.

"Na primeira etapa, são os esboços de Magalhães, Norberto, Pereira da Silva; as antologias de Januário, Pereira da Silva, Norberto-Adet, Varnaghen. Na segunda etapa, as biografias em série ou isoladas, de Pereira da Silva, Antônio Joaquim de Melo, Antônio Henriques Leal, Norberto; são as edições de Varnaghen, Norberto, Fernandes Pinheiro, Henriques Leal, etc. Na terceira, os 'cursos' de Fernandes Pinheiro e Sotero dos Reis, os fragmentos da história que Norberto não chegou a escrever".

Se a esta excelente exposição, forem acrescentados alguns daqueles nomes de historiadores e críticos estrangeiros do Romantismo que se preocuparam com a literatura brasileira e sobre ela escreveram, tais como Friedrich Bouterwek, Sismonde de Sismondi, Ferdinand Denis, Almeida Garrett, C. Schlichthorst, José da Gama e Castro, Alexandre Herculano e Ferdinand Wolf, todos antologizados por Guilhermino César em Historiadores e críticos do Romantismo. 1. A contribuição européia: crítica e_história literária, tem-se uma perspectiva mais ou menos completa dos esforços desenvolvidos, nos anos que correspondem ao nosso incipiente Romantismo, no sentido de estabelecer o quadro da literatura brasileira, através da reunião e edição dos textos, biografias dos autores e localização histórica das obras, enfim, o estabelecimento de um cânone literário, cujos primeiros delineamentos, apenas esboçados pelas várias e numerosas Academias do século XVIII, começam a se impor pela realização de obras de história literária mais coerentes e consistentes na representação da atividade literária no Brasil, tais como, por exemplo, os textos resultantes dos cursos de Fernandes Pinheiro, Curso de Literatura Nacional ou de Sotero dos Reis, Curso de Literatura Portuguesa e Brasileira, ou mesmo O Brasil Literário, de Ferdinand 
Wolf, todas dos anos 60 do século passado.

É bem de ver que as duas primeiras obras estudam os autores brasileiros entre portugueses, seja conjuntamente, como ocorre no caso de Fernandes Pinheiro, seja separadamente, como em Sotero dos Reis. O mesmo não acontece com a última história mencionada.

$\mathrm{Na}$ verdade, o livro de Ferdinand Wolf considera a literatura brasileira isoladamente, embora decorrente da portuguesa, e os autores e obras por ele tratados, com uma ou outra exceção, são expressões brasileiras já diferenciadas, ou em processo de diferenciação, das fontes portuguesas.

$\mathrm{Na}$ verdade, os autores e obras estudados por aqueles historiadores, depois de terem sido editados e selecionados por um Joaquim Norberto, por um Pereira da Silva ou por um Varnaghen, ou biografados por um Antônio Henriques Leal ou por um Antônio Joaquim de Melo, conforme o esquema mencionado de Antonio Candido, passaram a ser o núcleo daquele incipiente cânone literário que somente será ampliado, ou diminuído, por novos critérios de leitura dos textos literários, através das perspectivas históricas de um Sílvio Romero, ainda no século XIX, ou de um José Veríssimo já nos inícios do XX.

Por outro lado, embora diferentes e desiguais nos critérios de seleção, quase sempre, contudo, trazendo importante contribuição para o conhecimento de autores e obras, como é o caso de Joaquim Norberto na edição dos poetas mineiros do século XVIII ou o de Varnhagen na revelação de poemas de Gregório de Matos em seu Florilégio, os trabalhos realizados por esses estudiosos românticos, sem exceção, eram fundados no princípio básico da exaltação nacionalista das expressões brasileiras com relação às fontes européias. $\mathrm{O}$ critério era, portanto, o da diferenciação e da afirmação de autonomia.

Sendo assim, a escolha dos autores e das obras, e a conseqüente formação do cânone, se, por um lado, não podia fugir ao que, no plano dos conceitos, era tido por literatura segundo os teóricos metropolitanos, por outro lado, todavia, procurava ajustar aqueles conceitos a uma representação que desse conta dos anseios nacionalistas e, portanto, autonômicos. Isto, é claro, significa a sua permanência como vetor de orientação no discurso histórico-literário, e mesmo na obra de José Veríssimo, publicada em 1916, cuja concepção era indicadora de um desvio fundamental daquilo a que um crítico recente, Afrânio Coutinho, chamou de "tradição afortunada", isto é, a tradição nacionalista da crítica e da história literária, podia-se ler nos seus parágrafos de abertura:

"A literatura que se escreve no Brasil é já a expressão de um pensamento e sentimento que se não confundem mais com o português, e em forma que, apesar da comunidade da língua, não é mais inteiramente portuguesa".

Não obstante este incipit que, na verdade, articula o seu discurso históricoliterário ao dos nossos historiadores românticos, toda a tensão da obra de José Veríssimo está em como ajustá-lo ao próprio conceito de literatura que se expressa em outro momento da mesma "Introdução" à História da Literatura Brasileira. Ali, em trecho 
famoso, está dito:

"Literatura é arte literária. Esta é neste livro sinônimo de boas ou belas letras, conforme a vernácula noção clássica. Nem se me dá da pseudo novidade germânica que no vocábulo literatura compreende tudo o que se escreve num país, poesia lírica e economia política, romance e direito público, teatro e artigos de jornal e até o que se não escreve, discursos parlamentares, cantigas e histórias populares, enfim autores e obras de todo o gênero".

O alvo do último parágrafo é muito claro: Sílvio Romero e sua História da Literatura Brasileira, de 1888,que,dados os seus elementos de ampliação e a revisão a que submeteu o cânone do discurso histórico-literário romântico, fixou-se, por mais de meio século, não obstante os desvios e as oposições de um José Veríssimo ou mesmo de um Ronald de Carvalho e sua Pequena História da Literatura Brasileira, de 1919, como o repertório canônico por excelência da historiografia literária brasileira.

Herdeiro de toda aquela enorme tarefa de recuperação e transmissão de textos resultantes da atividade crítico-histórica dos estudiosos românticos, e fundado, em grande parte, naquela "novidade germânica" referida pejorativamente por Veríssimo, fazendo por isso, da história da literatura uma parte de mais ambiciosa história cultural, Sílvio Romero foi capaz de, por um lado, fazer da história literária um repositório da variada cultura do país e não apenas de sua literatura, e, por outro, graças a uma inteligência aglutinadora e sistemática, dar a seu discurso histórico-literário uma paixão interpretativa com relação ao quadro geral da cultura brasileira, que ainda mais se acentuava pelas características polêmicas de seu temperamento.

Obedecendo a uma divisão em três épocas que corresponderiam ao próprio desenvolvimento político e social do país ["período de formação $\{1500-1750\}$ ", "período de desenvolvimento autonômico \{1750-1830\}" e "período de transformação romântica \{1830-1870\}"], precedidas por um notável capítulo de metodologia e revisão de trabalhos anteriores, intitulado "Fatores da Literatura Brasileira", a História não apenas absorvia os cânones anteriores de extração setecentista ou romântica, mas apontava substituições e, ao mesmo tempo, às vezes num mesmo trecho, liquidava com as listas de autores erigidas pelo próprio Sílvio Romero.

É assim, por exemplo, o método adotado por ele ao considerar, no capítulo IX da segunda época, os "Últimos poetas clássicos", em que, depois de relacionar mais de vinte nomes "de algum mérito e outros sem merecimento algum", afirma, de modo cortante e definitivo:

"Eis aí uma grande lista de nomes obscuros. O leitor não se atormente; só dos dois últimos darei uma análise especial; os outros não a merecem".

$\mathrm{Na}$ verdade, os dois nomes excetuados poderão ser também obscuros para o leitor de hoje: Francisco Vilela Barbosa e Domingos Borges de Barros, o Visconde de Pedra Branca, podem ser tão desconhecidos quanto Luís Rodrigues Ferreira ou Antônio José Gomes da Costa, embora Os Túmulos do Visconde ainda hoje encontrem os seus leitores, dentre os quais o próprio Antonio Candido, que sobre eles tece interes- 
sante análise comparativa acerca do tema da morte do filho, envolvendo também Vicente de Carvalho e Fagundes Varela, logo nas páginas iniciais de sua Formação.

O leitor onívoro que foi Sílvio Romero teve também essa função: a de acrescentar nomes aos elencos preexistente de autores e obras, deixando pistas para leitores futuros mais perspicazes.

De qualquer modo, trazendo para a leitura histórico-literária o peso de uma formação cultural ampla, em que os métodos positivistas e evolucionistas, fossem inspirados em Taine ou Spencer, eram postos a serviço de uma urgência de interpretação do próprio desenvolvimento da sociedade e da cultura no Brasil, a História de Sílvio Romero impunha um certo discurso histórico-literário que foi decisivo na formação e fixação do nosso cânone literário, ao menos aquele que correspondia desde as primeiras manifestações literárias nos séculos XVI e XVII até à época de formação intelectual do próprio autor, isto é, o momento crucial de transformações empreendidas a partir de 1870, embora cometendo o grave erro de omitir os ficcionistas do século XIX. Deste modo, se aqueles séculos preenchem o primeiro volume da História, ao segundo corresponde as várias fases do que chama de Romantismo a partir de 1830.

Por outro lado, embora saiba enriquecer as suas leituras com a transcrição de numerosos textos exemplificativos, o que, sem dúvida, representava um enorme ganho para uma historiografia literária ainda mal aparelhada em termos de documentação textual, é preciso anotar que a retórica naturalista de Sílvio Romero não conseguia ultrapassar a urgência interpretativa de caráter sobretudo nacionalista que ele compartilhava com os seus antecessores românticos. E isto, sem dúvida, tem as mais funestas conseqüências para a constituição do cânone literário, pois a escolha do elenco de autores e obras termina por se definir pela maior ou menor capacidade em funcionar como instrumento de representação do país.

Assim, por exemplo, foi este critério de seleção a marca dominante daqueles compêndios escolares que atuaram como veiculadores do cânone nas escolas brasileiras, alimentadas, sobretudo, pelas versões mais reduzidas e portáteis do Compêndio de História da Literatura Brasileira, do próprio Sílvio Romero em co-autoria com João Ribeiro, cuja segunda edição, "refundida", é de 1909, ou mesmo a Pequena História, de Ronald de Carvalho, de 1919, que ,embora tivesse a vantagem cronológica de trazer o discurso histórico-literário até o Simbolismo de Cruz e Souza, se assentava em pressupostos da mesma ordem que a de Sílvio Romero.

Três anos antes da edição da obra de Ronald de Carvalho e no mesmo ano da morte do autor, 1916, mas aparecida postumamente, tinha sido publicada a História da literatura brasileira. De Bento Teixeira [1601] a Machado de Assis [1908], de José Veríssimo.

Era, sem dúvida, obra resultante de uma longa experiência de crítica e ensino: ao publicar a História, José Veríssimo tinha a seu crédito não apenas os volumes sobre educação, etnologia, cultura e literatura brasileiras publicados em sua fase paraense, mas, sobretudo, os volumes que reuniam os seus textos aparecidos na im- 
prensa do Rio de Janeiro, além da edição de algumas obras fundamentais da literatura brasileira como Marília de Dirceu, de Tomás Antônio Gonzaga, ou as obras de Basílio da Gama.

Neste sentido, pode-se, de fato, afirmar que a sua História é uma obra de síntese de toda a sua atividade; uma obra de sua maturidade intelectual, à diferença da de Sílvio Romero, que foi escrita em meio à sua exuberante carreira.

A obra tem grande coerência na ordenação de seus dezenove capítulos, precedidos por uma "Introdução" metodológica, já anteriormente citada, de importância para o estudo de nossa historiografia literária, percebendo-se por ela, por exemplo, como a influência contumaz do naturalismo de Taine é mitigada pela leitura de Gustave Lanson, de quem a Histoire de la littérature française, cuja primeira edição é de 1894, é citada, com aprovação, pelo escritor brasileiro a partir da edição de 1912.

Descontado o pequeno atraso, comum na recepção brasileira no que diz respeito às relações literárias com fontes estrangeiras, sobretudo críticas, a citação de Lanson, assim como a lembrança de Sainte-Beuve, que ocorre no final do texto introdutório, apontam para um esforço, que me parece ser a marca da tensão fundamental da obra de Veríssimo, como já tive a oportunidade de discutir em livro sobre o autor, no sentido de superar as amarras de sua formação intelectual como homem originário do ambiente cultural contaminado por aquilo que Sílvio Romero chamou de um "bando de idéias novas" [leia-se, sobretudo, evolucionismo e positivismo] e que o próprio Veríssimo, na História, vai caracterizar como "Modernismo". Sem complicar a periodização, aceitando como divisores os dois períodos da história política, isto é, o colonial e o nacional, Veríssimo, entretanto, não foge à regra que orientou todos os seus precursores: a definição de uma literatura brasileira, de um modo geral, é afirmada pela intensidade maior ou menor de um vago "espírito nacional", sempre pensado em confronto com as expressões metropolitanas.

Por outro lado, todavia, por ter da literatura uma concepção mais restrita, de certo modo menos conteudista e dando maior atenção aos elementos de formalização, que se deduz da afirmação da literatura como arte literária, a paixão interpretativa que fazia da leitura das obras literárias um modo ambicioso de leitura da cultura em geral, como está, sobretudo, em Sílvio Romero mas também em seus antecessores românticos, começa a ser minada por uma paixão analítica, embora de teor impressionista ou, antes, "humanista", como está no historicismo de Lanson, ainda que disfarçado pelas declarações de objetividade, como muito bem anotou Roland Barthes no ensaio Sur Racine.

Era o impasse com o qual tinha que se haver a obra de Veríssimo: uma espécie de aguda dilaceração entre a sua formação naturalista de crítico e as mais recentes manifestações da criação poética, dentre as quais avultava o Simbolismo, que exigiam uma ultrapassagem dos modelos de crítica inspirados naquela formação.

Deste modo, não incluiu os poetas simbolistas na História, embora a eles, isto é, aos dois principais, segundo o cânone estabelecido quer por Ronald de Carvalho, quer por Nestor Vítor, ou anteriormente por Araripe Júnior, Alphonsus de Guimaraens 
e Cruz e Souza, tenha consagrado ensaios isolados, de grande incompreensão é verdade, coletados nos Estudos de Literatura Brasileira. Assim como Lanson não soube ver a novidade revolucionária de Mallarmé, assim Veríssimo não conseguiu vislumbrar a importância da linguagem de um Cruz e Souza. Em termos de poesia, a História termina com os parnasianos sobre os quais Veríssimo encontrava o que dizer, sem se desfazer de sua herança naturalista.

É bem verdade, entretanto, que o impasse criado entre aquela herança e a concepção da literatura esboçada na "Introdução" à História é também responsável pelo modo mais arejado e mais adequado com que lê o Romantismo, que ocupa o centro da obra, e, por outro lado, que o faz abrir um capítulo especial, o último do livro, dedicado a Machado de Assis, percebido, a partir do seu momento, como culminância da literatura brasileira e parâmetro para o futuro.

Mais ainda, e isto é fundamental para a fixação do cânone de nossa literatura, sobressai a economia com que trata autores e obras dos séculos anteriores ao Romantismo, libertando-se da enumeração exaustiva, caótica e, muitas vezes, sem qualquer critério literário, que havia sido dominante em seus antecessores.

Sendo assim, por exemplo, os séculos XVI e XVII são reduzidos a sete autores e uma obra de autoria incerta em seu tempo: Bento Teixeira Pinto, José de Anchieta, Gabriel Soares de Souza, Fernão Cardim, Diálogo das Grandezas do Brasil, Frei Vicente do Salvador, Manuel Botelho de Oliveira e Gregório de Matos. Do mesmo modo, antes do que chama "A plêiade mineira", no século XVIII são elencados apenas cinco autores: Frei Manuel de Santa Maria Itaparica, Rocha Pita, Nuno Marques Pereira, Matias Aires e Domingos Caldas Barbosa.

Mas onde melhor, e mais adequadamente, se exerce a escolha seletiva e econômica do autor é, sem dúvida, nos estudos consagrados ao Romantismo em que, pela certeira classificação de duas gerações, precedidas por um capítulo sobre "predecessores do Romantismo" e seguidas por um outro sobre "os últimos românticos", abre capítulos intermediários muito importantes, quer sobre o que chama de "próceres do Romantismo", quer sobre "Gonçalves Dias e o grupo maranhense", estabelecendo, desta maneira, um quadro romântico de autores e obras que será dominante na historiografia literária de meio século depois.

Assim, enquanto naquele cria o espaço necessário para discutir alguns autores decisivos na formação do cânone romântico (e são estudados seis nomes: Porto-Alegre, Teixeira e Souza, Pereira da Silva, Varnaghen, Norberto e Joaquim Manuel de Macedo), neste outro, além de dar o destaque merecido a Gonçalves Dias, sabe valorizar a importância isolada do grupo que constituiu uma verdadeira "ilustração" brasileira no século XIX, elencando nomes como Odorico Mendes, Antônio Henriques Leal, Sotero dos Reis e João Francisco Lisboa, sem deixar de mencionar, com destaque, o poeta Joaquim Gomes de Souza, cuja atividade como tradutor de poesia era exaltada por seus contemporâneos, e Veríssimo anota a existência de uma "antologia de poemas líricos das principais línguas cultas" de sua autoria, embora tenha sido esquecida pelos pósteros. Não chegou, entretanto, a perceber a novidade da lingua- 
gem romântica de um outro Joaquim, Souzândrade, arrolando-o entre "homens de letras ou de saber, todos que com obras de vários gêneros e mérito continuaram até perto de nós o movimento literário da sua província pelo grupo primitivo iniciado". Mas este teria mesmo que esperar, como o próprio poeta previra, pela atividade historiográfica de quase meio século depois. E mesmo assim, uma historiografia reivindicatória de uma tradição brasileira de linguagem inventiva exercida pela vanguarda poética e crítica dos anos sessenta de nosso século.

Entre a obra rigorosa de José Veríssimo e esta historiografia de vanguarda, entretanto, o cânone da literatura brasileira, em função mesmo das inovações poéticas e ensaísticas que decorreram da ampla experimentação desencadeada pelo movimento modernista de 1922, sofreria o impacto do aparecimento, nos anos 50, de duas obras fundamentais da nossa historiografia literária: os seis volumes de $A$ literatura no Brasil, introduzida, organizada e dirigida por Afrânio Coutinho, cuja publicação se estendeu entre 1955, quando apareceram os dois primeiros volumes, e 1968, data de edição dos dois últimos, tendo o terceiro sido publicado em 1959, e os dois volumes da Formação da literatura brasileira. Momentos decisivos [1750-1880], de Antonio Candido, de 1959.

A primeira obra teve como propósito explícito a realização de uma história literária que, incorporando os dados do chamado "New criticism" anglo-americano, tratasse a Literatura Brasileira em termos estéticos e estilísticos, libertando-a das perspectivas naturalistas ou impressionistas ainda dominantes na Pequena História, de Ronald de Carvalho, ou mesmo nos dois volumes da História da literatura brasileira, de Arthur Mota, de 1930, e que dizem respeito aos séculos XVI, XVII e XVIII.

Deste modo, o princípio de base é a divisão da Literatura Brasileira em estilos de época: Era barroca, Era neo-clássica, Era romântica, Era realista, Era de transição, compreendendo o Simbolismo e o Impressionismo, e Era modernista, tudo precedido por um capítulo de "Generalidades" que, na verdade, corresponde ao primeiro volume, e sucedido por um outro de "Relações e perspectivas" e "Conclusão" que forma o sexto e último volume.

Esta concepção da obra, obrigando a tratar a literatura segundo critérios artísticos, se, por um lado, teve a enorme vantagem de procurar aprendê-la através de pressupostos estético-estilísticos, afastando alguns preconceitos de muito assentados em nossa historiografia literária como, por exemplo, a negação do Barroco ou a incompreensão com a escrita simbolista ou impressionista, nem sempre, por outro lado, é bem resolvida pelos inúmeros colaboradores, nem todos, é claro, afinados com tal concepção.

Sendo assim, se as diversas introduções escritas pelo organizador para os seis volumes revelam uma maturidade crítica e um amplo conhecimento das modernas correntes críticas que sustentam o excelente plano da obra, os ensaios particulares nem sempre correspondem aos propósitos ali fixados.

Deste modo, se, no primeiro volume, destacam-se, pela sistematização do conhecimento na área ou pela novidade de perspectiva, textos como o de Wilton Cardo- 
so sobre a língua literária, o de Câmara Cascudo sobre literatura oral e literatura popular, o de Fernando de Azevedo sobre a escola e a literatura ou o de Antonio Candido sobre o escritor e o público, o volume acaba ressentindo-se da ausência de textos que discutam a própria metodologia adotada na obra, isto é, ensaios que se indaguem pela própria condição estético-estilística da literatura em relação, inclusive, com os tópicos abordados no volume. Do modo como foram concebidos e realizados, os ensaios do primeiro volume parecem descender, muito proximamente, daquelas indefectíveis introduções que estão sempre presentes nas histórias literárias de corte naturalista.

De qualquer modo, a obra representou uma ruptura, ao menos de propósito, com relação à tradição naturalista iniciada por Sílvio Romero - daí, no último volume, Afrânio Coutinho falar explicitamente de compromisso anti-romeriano da obra , e, se por um lado, dá continuidade ao cânone de autores e obras fixado dentro daquela tradição, por outro lado, em casos isolados, e graças aos esforços individuais de alguns colaboradores, acrescenta nomes e obras àquele cânone. Refiro-me, sobretudo, aos estudos de Andrade Muricy sobre o Simbolismo -Muricy é também o responsável pelos volumes antológicos do Simbolismo, intitulados Panorama do movimento simbolista brasileiro -, ou mesmo o texto de Fausto Cunha sobre o Romantismo, em que já vem destacada a singularidade de Souzândrade dentro daquele movimento. Ou mesmo os estudos acerca do regionalismo na ficção, no volume dedicado à "Era realista", através de uma classificação em ciclos - nortista, nordestino, baiano, central, paulista e gaúcho -, em que muitos autores e obras são recuperados e interpretados para o conjunto da literatura brasileira, como é o caso dos nortistas Alberto Rangel, o José Veríssimo ficcionista das Cenas da vida amazônica ou Viana Moog, dos nordestinos Oliveira Paiva, o Araripe Júnior ficcionista, Carneiro Vilela ou Mário Sete, dos baianos Xavier Marques, Muniz Barreto ou Elvira Foepell, dos mineiros e goianos Felício dos Santos, Afonso Arinos, Godofredo Rangel ou Hugo de Carvalho Ramos, dos paulistas Valdomiro Silveira, Cornélio Pires ou Hilário Tácito, dos gaúchos Caldre Fião, Apolinário Porto Alegre, Alcides Maia ou Simões Lopes Neto.

Enfim, um conjunto de autores e obras do momento realista que apontam para a tradição regionalista na literatura brasileira que vai atingir o seu apogeu e maior refinamento estilístico na década de 30 do século XX com um Graciliano Ramos, um José Lins do Rego ou mesmo, no extremo sul, um Érico Veríssimo. Mais uma vez, entretanto, é preciso dizer que os ensaios correspondentes a cada um dos ciclos são muito diversos em suas perspectivas de abordagem e em seu alcance crítico, indo desde o mais ingênuo impressionismo e puro e simples levantamento de dados, datas, autores e obras, como no caso de Aderbal Jurema no que se refere ao ciclo nordestino, até às atiladas observações de um crítico analista, no que diz respeito ao ciclo gaúcho, como Augusto Meyer.

Sendo assim, lida com o discernimento crítico adequado, a obra organizada por Afrânio Coutinho representou, sobretudo no momento de sua publicação, a possibilidade de uma leitura mais ventilada do cânone da literatura brasileira, quer 
reorientando este mesmo cânone, como nos exemplos mencionados do Barroco ou do Simbolismo, que a ele acrescentando elementos que, mais tarde, serão importantes e mesmo decisivos para leituras de movimentos ou autores contemporâneos - caso do Regionalismo de 30 ou da obra de um João Guimarães Rosa e um seu precursor, como o gaúcho Simões Lopes Neto.

Embora existissem esforços anteriores que, às vezes vagamente, acenassem para uma abordagem semelhante, e é bastante lembrar a concepção da literatura como arte literária de José Veríssimo, ou mesmo a noção estetizante e impressionista de uma literatura luso-brasileira tal como era defendida por Antônio Soares Amora em sua História da literatura brasileira, publicada no mesmo ano, 1955, de aparecimento de A literatura no Brasil, esta, de modo mais consistente e em maiores dimensões, fazia a defesa explícita daquele método, embora nem sempre, como já se viu, atingisse a sua plena realização, dada a heterogeneidade de seus colaboradores.

Um deles, Antonio Candido, estabeleceria uma espécie de compromisso entre a herança naturalista, e não me refiro apenas à tranqüila auto-definição romeriana mas, sobretudo, ao impasse que se registra na obra de José Veríssimo, e uma leitura analítica da obra literária inspirada também em abordagens aprendidas quer com o "New criticism", quer com a Estilística de um Leo Spitzer, ou, mais ainda, de um Erich Auerbach.

$\mathrm{O}$ resultado foram os dois volumes que constituem a Formação da literatura brasileira. Momentos decisivos [1750-1880], publicados em 1959, mas, segundo informação do próprio autor, redigidos entre 1945 e 1951 e revistos nos anos de 55, 56 e 57, ano em que assina o prefácio da obra. [Assinale-se, entre parêntese, que é do mesmo ano de 1959 a publicação do primeiro volume, de um conjunto de oito, de uma obra que é um marco da historiografia literária publicada no país, embora não trate da literatura brasileira, a não ser muito marginalmente, e ser escrita por um brasileiro de adoção: refiro-me à História da literatura ocidental, de Otto Maria Carpeaux, em que se busca aplicar ao estudo da literatura, historicamente considerada, o método estilístico-sociológico, aproximando-a por aí quer do projeto da obra de Afrânio Coutinho, quer da obra de Antonio Candido, como se verá].

Tendo por objetivo o amplo estudo de três momentos da literatura no Brasil o Arcadismo, a Ilustração e o Romantismo -, talvez o principal traço distintivo da Formação seja o deslocamento do eixo de aproximação histórica à nossa literatura: em lugar de uma perspectiva eminentemente interpretativa, que dominara toda a nossa tradição histórico-crítica, na obra de Antonio Candido se acentua e se intensifica o eixo analítico, o que significa dizer que não se utiliza a literatura como veículo de uma interpretação cultural mas, respeitando-se a sua autonomia como obra de arte, busca-se estabelecer caminhos de acesso àquela.

Por outro lado, embora tenha uma forte e bem construída interpretação do lugar da literatura na cultura brasileira em geral, as relações de interdependência entre autor, obra e público que embasam a noção de sistema literário como, teoricamente, oposto à noção de manifestação literária, e que, ao mesmo tempo, asseguram a 
coerência das análises particulares e permitem o revezamento constante entre história e literatura, isto não oblitera a predominância do juízo crítico fundado na análise literária. Num determinado passo do "Prefácio", o autor deixa explícita a trama compositiva da obra, ao afirmar:

"A base do trabalho foram essencialmente os textos, a que se juntou apenas o necessário de obras informativas e críticas, pois o intuito foi não a erudição, mas a interpretação, visando o juízo crítico, fundado sobretudo no gosto".

O que faltou dizer, para que a trama se completasse, e é, certamente, dado como óbvio, é que entre a interpretação e o juízo crítico resultante, ainda que tendo por base um vago "gosto", estava o momento decisivo da análise, sem o que aquele juízo, ainda mais se confundido com o "gosto", nada teria de crítico. E esta nossa interpretação encontra o seu respaldo na própria obra, em que os capítulos mais gerais de preparação à leitura individualizada dos textos literários, sobretudo no primeiro volume, quando são discutidos conceitos culturais como razão, natureza e verdade a fim de apreender a figura a extrair do nosso século XVIII, não apenas servem de fundo às obras literárias surgidas dos movimentos academicistas, em que se singulariza a de Sousa Nunes, mas já aparecem como resultantes da leitura das complexidades impostas pela posição de intervalo assumida pela poesia de Cláudio Manuel da Costa. Que estas complexidades sejam antes extraídas da leitura dos poemas de Cláudio do que decorrentes de uma aproximação interpretativa daqueles conceitos de cultura, é marca do pendor analítico do método histórico-literário do autor.

Neste sentido, por exemplo, é fundamental que a leitura da poesia de Cláudio, encontrando a sua metáfora crítica essencial na relação entre a rocha, como imagem recorrente, e a brandura como sentimento contrastante, não venha a escamotear a presença de elementos de toda ordem, os sociais, os históricos e psicológicos que, por assim dizer, são resolvidos na estrutura estética da obra. É esta resolução, quer dizer, este resultado enquanto obra literária, que define o lugar da poesia de Cláudio no sistema literário, instituído pelo sentido quer da história em geral, quer da história literária em particular.

Este modelo de análise domina a Formação, e ainda no primeiro volume é o que permite as caracterizações arcádicas dos poetas pertencente àquela "plêiade mineira", na expressão de José Veríssimo, lidos por todos os antecessores da tradição histórico-literária. Se não há novidade no sentido da fixação canônica, a leitura agora empreendida, dado o seu teor fortemente analítico e judicativo, o que vem acrescentar são, sobretudo, argumentos mais fortes e plenos para a própria canonização.

No entanto, ainda neste primeiro volume, é possível indicar um momento de salto na leitura do cânone de nossa literatura. Refiro-me ao capítulo VII, "Promoção das luzes", em que são articulados os elementos que, através de alguns nomes e obras, construiram uma espécie de Ilustração Brasileira, a "nossa Aufklärung", como a denomina o próprio Antonio Candido. Nomes como Sousa Caldas, Antônio Ferreira de Araújo Guimarães, o diretor de O Patriota, Hipólito da Costa, do Correio brasiliense, Frei Caneca ou Evaristo da Veiga, todos autores do que Antonio Candido chama de 
"gêneros públicos", são resgatados da história política para a literária por meio de pertinentes análises textuais e de estilo, construindo o crítico, às vezes, metáforas de grande eficácia como, por exemplo, ocorre ao tratar do estilo de Evaristo da Veiga, em trecho onde cita até mesmo Roland Barthes, quando ainda era muito pequena a voga do crítico francês no país:

"Como escritor é fácil e correto, abandonando poucas vezes o tom de serenidade, objetivo e simples. O seu período tende à largueza, como era comum no tempo, e quando o ardor da argumentação o empolga chega a ser muito extenso, cortado de subordinadas, sem perder a clareza e o fio. Se retomarmos a imagem proposta mais alto, e imaginarmos a pena como algo orgânico ao escritor, fazendo parte do seu corpo e prolongando no contacto com a página o ritmo da sua vida, diremos, à maneira simbólica de Roland Barthes, que o de Hipólito da Costa é um estilo encéfalo, o de Frei Caneca um estilo sangue, o de Evaristo um estilo linfa. Necessário à vida, mas pálido, evocando idéias de serenidade e mediania".

Da mesma maneira, ainda que se conservando obediente ao cânone tradicional da literatura romântica no Brasil, em que os autores e as obras destacadas são, em síntese, aquelas mesmas examinadas por seus antecessores, são as análises e não apenas a afirmação de importância interpretativa, que operam ponderáveis deslocamentos no modo de fixá-las em nosso cânone literário.

Sendo assim, por exemplo, a própria obra escolhida para marcar a intensidade do indianismo em Gonçalves Dias, o poema "Leito de folhas verdes", renova as abordagens ao poeta, na medida em que as observações de leitura procuram uma sutura de elementos significativos a partir dos aspectos da composição, por assim dizer, técnicos do verso, em que ritmos e imagens produzidos pela linguagem são privilegiados como agenciadores dos mais profundos significados do texto.

Assim também, a idéia central da nossa ficção romântica como "um instrumento de descoberta e interpretação", tal como se propõe no capítulo III, em que se destacam as leituras de Teixeira e Sousa e Joaquim Manuel de Macedo, consegue operacionalizar uma releitura do "aparecimento da ficção" no Brasil, fugindo aos cacoetes críticos usuais, acenando para a atividade ficcional como meio de representação literária que, ao mesmo tempo, que decorre, acrescenta elementos de invenção à leitura da realidade.

É não somente a análise da ficção mas a ficção como análise: uma invenção crítica que somente a tensa relação entre o historiador e o crítico, sabendo impregnar o discurso histórico-literário com elementos fundamentais do discurso crítico-teórico, consegue expressar.

Não se veja aí, entretanto, apenas a contribuição teórica dos movimentos críticos mais ou menos contemporâneos do autor, como a Estilística ou o "New criticism": para a sua percepção de tais autores e obras da literatura brasileira foram essenciais os próprios poetas saídos do Modernismo de 22, destacando-se os dois que também foram poetas-críticos: Mário de Andrade e Manuel Bandeira. É, sem dúvida, com eles, além, é claro, com seus antecessores de historiografia literária, que dialoga o 
método crítico de Antonio Candido, ou melhor a escrita crítica dele, acerca da poesia e da prosa de ficção do romantismo. Não é de estranhar: à disposição, estavam os ensaios e as valiosas antologias de Manuel Bandeira para os poetas, ou as observações interpretativas, de traço muito pessoal, de Mário de Andrade quer sobre os poetas, como, por exemplo, Álvares de Azevedo, quer sobre a prosa de ficção, bastando lembrar José de Alencar ou Manuel Antônio de Almeida.

Por outro lado, todavia, a pressão sobre o cânone romântico, neste segundo volume da Formação, é exercida sobretudo, de maneira marginal, em sub-capítulos que, em geral, trazem a denominação de "menores".

Neste sentido, vale a pena assinalar o trecho do capítulo II, "Os primeiros românticos", em que trata de Francisco Otaviano, intitulado "Otaviano, burguês sensível", quando solicita uma maior atenção dos críticos para a obra do autor, salientando a sua qualidade como tradutor de poesia e Antonio Candido enumera os poetas por ele traduzidos: Horácio, Catulo, Alfieri, Byron, Shelley, Ossian, Moore, Musset, Victor Hugo, Uhland, Goethe, Schiller, Shakespeare, ainda à espera de uma oportuna edição moderna, acrescente-se sabendo dar à tradução poética um valor que não era tão usual no tempo do crítico quanto se possa imaginar no nosso em que é tida em alta conta.

Tanto a obra organizada por Afrânio Coutinho, quanto a de Antonio Candido surgiram num momento de grande efervescência cultural no Brasil, decorrente, sobretudo, do projeto desenvolvimentista desenhado para o país pela política de Juscelino Kubitschek.

Na verdade, seguindo-se à I Bienal de Arte de São Paulo, em 1951, e coincidente com as comemorações do IV Centenário da cidade, em 1954, logo nos anos seguintes assistia-se a, pelo menos, três acontecimentos literários marcantes: num mesmo ano, 1956, eram publicadas as duas obras mais importantes de João Guimarães Rosa, o conjunto de novelas Corpo de baile e Grande Sertão:Veredas, os poemas reunidos de João Cabral de Melo Neto, Duas águas, e acontecia a exposição de Poesia Concreta, marcando, por assim dizer oficialmente, a presença de uma vanguarda de corte internacionalista no país.

Por outro lado, aquilo que as obras do ficcionista e do poeta traziam para o centro do debate crítico, quer dizer, a invenção de uma literatura em que os traços localistas, herdeiros quer do regionalismo realista-naturalista, quer do regionalismo dos anos 30, e os cosmopolitas, herdeiros do movimento de modernização desencadeado pela Semana de 22,eram tensamente enfrentados e resolvidos por uma linguagem inovadora, foram como já se viu, reconsiderados pelas duas obras de historiografia literária, ainda que tivessem um maior peso na reflexão e no próprio estilo de Antonio Candido, não obstante o esforço inovador de método perseguido pela obra dirigida por Afrânio Coutinho.

Deste modo, num determinado momento, mais ou menos até o Golpe Militar de 1964 e seus desdobramentos funestos, para a cultura, nos anos que se seguiram, a reflexão histórico-crítica, com ênfase na de Antonio Candido, era coincidente no mais 
importante, isto é, numa leitura em que conviviam a nota ideológica e a autonomia relativa da criação literária, com as propostas da vanguarda, sobretudo a concreta, com destaque para os seus poetas-críticos da primeira hora, isto é, Augusto e Haroldo de Campos e Décio Pignatari. [Diga-se, de passagem, que exemplos do diálogo fertilizador entre tais reflexões e a prática da literatura foram dados nos dois Congressos de Crítica e História Literária que se realizaram nos inícios dos anos 60, o de Assis, SP, em 1961, e o de João Pessoa, PB, em 1962].

Foi precisamente neste último Congresso que, através de trabalhos apresentados por alguns de seus participantes, três autores maranhenses do século passado eram repensados por novas leituras críticas que buscavam incluí-los, de modo mais eficaz, no cânone literário brasileiro: João Francisco Lisboa, Odorico Mendes e Souzândrade. Refiro-me, sobretudo, aos textos de Luís Costa Lima sobre o poeta do Guesa e de Haroldo de Campos sobre a criação daquilo que o poeta concreto vai chamar, mais tarde, de tradução/invenção por Odorico Mendes.

Era, na verdade, o início de reconsideração do cânone literário, com especial ênfase na poesia, mas não apenas, desenvolvida pelos poetas concretos que terá como resultado, logo a seguir, no ano de 1964, a publicação do volume ReVisão de Souzândrade, de Augusto e Haroldo de Campos, com ensaio de Costa Lima e colaboração bibliográfica de Erthos de Souza, ou, um pouco mais tarde, os ensaios introdutórios de Haroldo de Campos às reedições de Oswald de Andrade, dirigidas por Antonio Candido, ou, mais tarde ainda, a releitura dos Simbolistas realizada por Augusto de Campos, de onde resultou o livro ReVisão de Kilkerry, em 1971, e os textos posteriores sobre Maranhão Sobrinho e Ernâni Rosas.

Se é possível ver em todo este enorme e fértil trabalho de releitura e revisão do cânone por parte dos poetas de vanguarda [e é preciso não esquecer também os ensaios de recuperação de um outro vanguardista, Mário Chamie, sobre Hilário Tácito e seu romance Madame Pommery] um gesto reivindicatório com relação ao passado literário pela construção de um conjunto de autores precursores da própria vanguarda, o que, no mais, segue o que há de mais inventivo na literatura de todos os tempos e lugares, o que mais importa é o deslocamento do paradigma histórico-literário: de uma visão linear e somente diacrônica da história literária para uma percepção das intersecções sincrônicas operadas naquela visão.

Informados por concepções lingüísticas de grande interesse para as reflexões poéticas, como as de Roman Jakobson, por exemplo, mas, sobretudo, fundados na própria experiência criadora com a linguagem poética, tais poetas-críticos representam também a vanguarda na leitura de nosso cânone literário e mesmo que não se esteja de acordo com os seus gostos e escolhas [como parece ser o caso, para citar somente o maior de seus interlocutores, Antonio Candido, no que se refere à releitura das traduções dos clássicos gregos e latinos por Odorico Mendes], é inegável a contribuição revisionista para uma literatura tão esvaziada, quanto a brasileira, de verdadeiros gênios inventivos, sobretudo se se anota que tais leituras e revisões têm sempre se exercitado para a adição e não para a exclusão de autores e obras. 
É o caso recente da leitura que faz Haroldo de Campos da Formação da Literatura Brasileira, especificamente sob o ângulo do problema da origem da literatura brasileira - o que, por caminho diverso, já havia sido tratado por Afrânio Coutinho no ensaio dedicado à obra de Antonio Candido do mesmo ano de sua publicação, 1959, hoje fazendo parte do livro Conceito de literatura brasileira, de 1981-, intitulado $O$ seqüestro do barroco na formação da literatura brasileira: o caso Gregório de Matos, de 1989.

Neste ensaio, mais do que polemizar com o autor da Formação no que diz respeito ao que chama de visão substancialista da história em Antonio Candido, o que se traduziria numa percepção teleológica da literatura, no caso da brasileira e do autor da Formação, guiada pela noção de "espírito nacional" de nossa tradição historiográfica e que, por isso, haveria de privilegiar o Romantismo com a conseqüente recusa do Barroco, Haroldo de Campos busca num conceito de literatura que se suporte antes na função poética da linguagem do que em suas funções referenciais e emotivas, segundo os termos da lição de Jakobson, os argumentos essenciais não apenas para o resgate da voz barroca de Gregório de Matos mas os elementos com os quais possa trabalhar uma outra história literária, aquela das intersecções sincrônicas e não apenas linear e diacrônica já referida.

É, deste modo, uma operação de adição, isto é, no sentido de anotar o que chama de "seqüestro do barroco" e pedir a inclusão, em nosso sistema literário, do nome e da obra, ainda que muito disputada em sua autenticidade filológica, de Gregório de Matos.

Mais ainda, todavia, é uma espécie de resumo daquelas idéias para a construção de uma história literária de corte sincrônico que já eram trabalhadas nas várias revisões empreendidas anteriormente.

Neste sentido, é, sem dúvida, essencial para uma discussão acerca da formação do cânone da literatura brasileira e, certamente, deverá contar para a nossa historiografia literária posterior.

Como alguma coisa das revisões passadas da vanguarda contou para, ao menos, duas histórias literárias publicadas nas décadas de 70 e 80 . Refiro-me à História concisa da literatura brasileira, de Alfredo Bosi, de 1970, e a História da literatura brasileira, em quatro volumes, de Massaud Moisés, de 1983-86.

Para ficar somente no caso mais famoso de revisão, em ambas o poeta Souzândrade merece um destaque que não havia merecido nas histórias anteriores, com exceção do ensaio mencionado de Fausto Cunha incluído em A literatura no Brasil. No entanto, o que nessas histórias não conta é a própria discussão acerca do discurso histórico-literário com tanta intensidade problematizado pelas vanguardas.

Hoje é cada vez mais evidente que a história não se define apenas como tarefa de acumulação de datas e dados mas que impõe, para a sua própria efetivação, uma metalinguagem que se volte para o discurso histórico.

Este será, com toda a probabilidade, o trabalho principal de uma historiografia literária para o futuro. 